\title{
LA REPRESENTACIÓN DE LO REAL EN STENDHAL Y ALEJO CARPENTIER (UN ESTUDIO COMPARATIVO Y NARRATOLÓGICO DE LA CHARTREUSE DE PARME Y LA CONSAGRACIÓN DE LA PRIMAVERA)
}

\author{
THE REPRESENTATION OF REALITY IN STENDHAL \\ AND ALEJO CARPENTIER (A COMPARATIVE STUDY \\ AND NARRATOLOGICAL OF LA CHARTREUSE DE PARME \\ AND LA CONSAGRACIÓN DE LA PRIMAVERA)
}

\author{
Emilio Ernesto DELGADO CHAVARRÍA \\ Crítico literario \\ emiliodelg@gmail.com
}

Resumen: Este trabajo analiza la manera en que Stendhal (1783-1842) y Alejo Carpentier (1904-1980) representan la realidad. Para ello, el estudio examina el conflicto narrativo, el orden en la organización del texto y la acción narrativa, siendo el corpus seleccionado La Chartreuse de Parme (1839) y La consagración de la primavera (1978).

Palabras clave: Stendhal. La Chartreuse de Parme. A. Carpentier. La consagración de la primavera. Literatura comparada. Narratología. Realismo.

Abstract: This paper analyzes the way Stendhal (1783-1842) and Alejo Carpentier (1904-1980) depict reality. It starts with the analysis of the narrative conflict, the structure of the story and the narrative action. The stories selected are La Chartreuse de Parme (1839) and La consagración de la primavera (1978).

Key Words: Stendhal. La Chartreuse de Parme. A. Carpentier. La consagración de la primavera. Comparative literature. Narratology. Realism. 


\section{INTRODUCCIÓN}

El objetivo de este trabajo es comparar la representación de la realidad en la narrativa de dos escritores que pertenecieron a tiempos y a culturas diferentes. Nos aproximaremos al escritor francés de principios del siglo XIX, Henri Beyle (1783-1842), cuyo seudónimo es Stendhal, y al escritor cubano de finales del siglo XX, Alejo Carpentier (1904-1980).

Debemos tener en cuenta que la comparación literaria suele justificarse a partir de las influencias (mediante el estilo, el pensamiento o las ideas en otro escritor), o por la similitud de temas que versen sus escritos. Por esa razón, es necesario precisar que en este estudio las causas de la comparación no se encuentran en estos elementos. El auténtico motivo es estructural. Stendhal y Carpentier son escritores realistas ${ }^{1}$, sus escrituras tiene el propósito de narrar acontecimientos reales ${ }^{2}$, por ello pretendemos identificar los procedimientos formales que realizan para evocar la realidad, es decir, vamos a revelar los mecanismos literarios empleados para la descripción de hechos o acontecimientos.

Así pues, dado que nuestro enfoque es meramente formal, y debido a que concebimos la novela como el relato de un conflicto ${ }^{3}$, el análisis comparado se desarrollará en base

1 Por supuesto, el realismo de cada uno de ellos es diferente. En Stendhal se asocia al romanticismo (Del Prado, 2009: 852-853), y el realismo de Carpentier se define mediante el término "real maravilloso" (Franco, 2009 [1973]: 301). Pero, precisamente, estas diferencias nos estimulan a comparar en sus textos las distintas maneras de reproducción de la realidad.

2 Existe un factor en ambos escritores que los diferencia de los novelistas contemporáneos, a saber: una voluntad en sus escrituras que exige al lector leer sus textos como algo que remite a un hecho, a un acontecimiento o a una experiencia personal, es decir, hay una intención de evocar el mundo real. Esta intención puede identificarse en sus obras en los elementos que Gérard Genette llamó paratextes: "L'œuvre littéraire consiste, exhaustivement ou essentiellement, en un texte, c'est-à-dire (définition très minimale) en une suite plus ou moins longue d'énoncés verbaux plus ou moins pourvus de signification. Mais ce texte se présente rarement à l'état nu, sans le renfort et l'accompagnement d'un certain nombre de productions, elles-mêmes verbales ou nom, comme un nom d'auteur, un titre, un préface, des illustrations [...]. Cet accompagnement, d'ampleur et d'allure variables, constitue ce que j'ai baptisé ailleurs, conformément au sens parfois ambigu de ce préfixe en français [...] le paratexte de l'ouvre" (Genette, 2002 [1987]:7). Las novelas de ambos escritores siempre llevan un proemio o un apéndice que certifica que la obra literaria está basada en algún hecho real o experiencia de vida. Por ejemplo, en la edición de Alianza Editorial de La consagración de la primavera, el texto va acompañado de un apéndice, donde el escritor certifica que el origen de su relato son sus vivencias de la guerra civil española: "Conocí, combatiendo en las filas de las Brigadas Internacionales, al hijo de un banquero neoyorquino" (Carpentier, 2004 [1978]:665). Lo mismo sucede con Stendhal, pues La Chartreuse de Parme va precedida de un avertissement que certifica que el autor escuchó la historia de Sanseverina de un conocido de ella: "L'aimable nièce du chanoine avait connu et même beaucoup aimé la duchesse Sanseverina, et me prie de ne rien changer à ses aventures, lesquelles son blâmables" (Stendhal, 2000 (1839):17). Así pues, los paratextes en Stendhal y Carpentier tienen una marcada intención mimética.

3 Partimos de la idea que Lukács tenía acerca de la novela, según la cual ésta es la epopeya de un mundo problemático: "La novela es la epopeya de una época en que la totalidad extensiva de la vida ya no está 
a tres categorías: estructura del conflicto, orden en la organización del texto y acción narrativa.

Cuando decimos estructura del conflicto hacemos referencia a la manera en que el escritor configura el problema que relata la novela, es decir, indagaremos en la forma que se construyen los eventos que complican la historia.

En relación con el orden de la organización del texto, este es el principio rector que orienta la vinculación de los acontecimientos que integran el relato. Todorov, basándose en algunos criterios de Tomachevski, los divide en aquellos regidos por un orden lógico y temporal, y los que son dominados por un orden espacial:

Siguiendo una sugerencia de Tomachevski, distinguiremos dos tipos principales de organización del texto: "La disposición de los elementos temáticos se realiza de acuerdo con dos tipos principales: o bien obedecen al principio de causalidad inscribiéndose dentro de una cierta cronología o bien son expuestos sin consideración temporal, o sea una sucesión que no toma en cuenta ninguna causalidad interna" [...] Al primero tipo denominaremos "orden lógico y temporal", y al segundo -que Tomachevski identifica negativamente- "orden espacial" (Todorov, 2004 [1968]: 111).

Los episodios vinculados por un principio lógico son acontecimientos que a su vez son causa y efecto de otros eventos, es decir, predomina la causalidad. Todorov (2004 [1968]: 115) denomina a este tipo de relatos mitológicos; mientras que en los eventos temporales no existe una relación directa de causalidad, son pasajes narrativos que tienen la función de ilustrar una idea, de precisar una visión de mundo, de ahí que Todorov (2004 [1968]: 115) los Ilame ideológicos. Nosotros llamaremos a este tipo de eventos temporales-ideológicos, mientras que en los que existe causalidad pura les denominaremos simplemente causales. Téngase presente que tanto en uno y otro hay temporalidad, es decir, hay un relato. No así en los textos vinculados por relaciones de tipo espacial, estos son únicamente hechos descriptivos, pero sin relato. Tradicionalmente, en lo que a la prosa se refiere, suelen ubicarse dentro de esta categoría los diarios de viajes. Otra situación a tener en cuenta es que un texto puede presentar fragmentos vinculados por cualquier tipo de relaciones al mismo tiempo. No obstante, solo hay un tipo que prevalece, convirtiéndose este en principio rector. Tal principio es el que tratamos de identificar.

directamente determinada, en que la inmanencia del sentido a la vida se ha vuelto un problema, pero que aún busca la totalidad" (Lukács, 2010 [1920]: 49). 
Finalmente, analizaremos los elementos que dinamizan el relato, la acción narrativa. Este factor se encuentra vinculado al tiempo, porque dependiendo de cómo se configure la acción, así será la percepción del tiempo del relato.

En cuanto a las obras que vamos a examinar, en el caso de Stendhal se estudiará $L a$ Chartreuse de Parme, publicada por primera vez en 1839 en la editorial Ambroise Dupont de París; y en lo que respecta a Carpentier se analizará La consagración de la primavera, publicada en 1978 por la editorial Siglo XXI Editores de México D.F.

\section{ESTRUCTURA DEL CONFLICTO}

Entre los aspectos positivos que Balzac (1972 [1840]) señala de La Chartreuse de Parme se encuentran la fuerza del pensamiento político que subyace en la obra (Balzac, 1972 [1840]: 626) y la fineza de la observación psicológica (Balzac, 1972 [1840]: 634). Alaba además lo bien que están creados los personajes, en especial los de Gina y Mosca (Balzac, 1972 [1840]: 627, 628). La crítica negativa se centra en dos elementos principales: la falta de una técnica narrativa (méthode) (Balzac, 1972 [1840]: 629) y el estilo particular de Stendhal (Balzac, 1972 [1840]: 631). Advierte (Balzac, 1972 [1840]: 629) que uno de los retos de La Chartreuse de Parme es la composición de la trama, Stendhal narra los hechos tal y como suceden, por lo que recomienda al autor eliminar cinco capítulos 5 . También indica (Balzac, 1972 [1840]:\#630) que uno de los principales problemas del texto es que el autor quiere abarcar dos grandes temas al mismo tiempo, lo que provoca que el relato sea leído como una narración comprimida, haciendo que la concatenación de los hechos resulte muy ajustada, como si hubiera sido realizada apresuradamente. Por una parte Stendhal quiere contar la vida de Fabrice, el héroe de la novela y, por otra pretende relatar las intrigas políticas de la corte de Parma. Pero para narrar la vida de Fabrice sería preciso que la intriga política quedara relegada a un segundo plano, y sería necesario además restarle fuerza a los demás personajes (Gina y Mosca), pues opacan a Fabrice. La cuestión es complicada, ya que al contraponer lo que Fabrice encarna (la ausencia de pasión) y lo que Gina y Mosca representan (la astucia, la inteligencia y el cálculo político), sobresale el genio de estos últimos. De ahí que sea necesario dotar a Fabrice de mayor complejidad para que no se vea anulado por los personajes que lo rodean. Tal medida

4 Todas las referencias a la crítica que Balzac hizo a La Chartreuse de Parme provienen de la reseña que publicó el autor en la Revue parisienne, el 25 de septiembre de 1840: Études sur M. Beyle (Frédéric Stendhal).

5 Balzac le propone comenzar la novela por la batalla de Waterloo sintetizando todo lo anterior, es decir, suprimiendo la historia familiar de Fabrice: "Aussi souhaiterais-je, dans l'intérêt du livre, que l'auteur commençât par sa magnifique esquisse de la bataille de Waterloo, qu'il réduisit tout ce qui la précède à quelque récit fait par Fabrice ou sur Fabrice pendant qu'il gît dans le village de Flandre où il est blessé" (Balzac, 1972 [1840]:629). 


\section{DE LA PRIMAVERA)}

no deja de ser problemática, debido a que obligaría al escritor a reconfigurar el papel de su protagonista.

En relación con el estilo, Balzac (1972 [1840]: 631) critica la parquedad del narrador en la descripción de lugares y ambientes, Stendhal únicamente enfatiza en las montañas y en los lagos, dejando fuera del foco narrativo los demás sitios por donde transita su héroe. Parma, Bolonia, Milán, Turín y París apenas son mencionadas, razón por la cual es difícil hacerse una imagen mental de cómo es el ambiente de esas ciudades. Además, Balzac (1972 [1840]: 631) identifica ciertos errores gramaticales, tales como la utilización incoherente de tiempos verbales, oraciones sin verbo, frases largas mal construidas, frases cortas sin ritmo y demasiados artículos (c'est, ce que y que); fallos que fatigan la lectura de la novela. Balzac (1972 [1840]: 631) justifica estas negligencias por el estilo particular del escritor, que se oponía a la forma clásica predominante entonces en Francia, estilo que privilegiaba la claridad de la prosa. Stendhal iba a contrasentido, pues otorgaba mayor importancia al pensamiento que a la precisión narrativa. Balzac (1972 [1840]: 632) lo excusa afirmando que Stendhal es más bien un pensador, un filósofo en la misma tradición de Diderot, y no un artista. Es decir, para Stendhal la literatura solo es el medio para transmitir su pensamiento, por lo que no se preocupa por la expresión artística, sino por la filosofía de su mensaje y, como le sucede a cualquier filósofo, el lenguaje, en vez de ser su aliado, se convierte en su principal obstáculo.

En general, buena parte de la crítica literaria posterior a Balzac continuó sus líneas de interpretación ${ }^{6}$. Concretamente, se dedican a explicar el particular realismo de Stendhal, que se desarrolla en oposición al realismo estipulado por Flaubert y por el mismo Balzac. En este sentido, el realismo stendhaliano no es más que la justificación teórica de los defectos que Balzac encontró en las descripciones de paisajes y ambientes de $L a$ Chartreuse de Parme. No obstante, estos supuestos defectos no eran otra cosa que el propio estilo narrativo de Stendhal?.

Esta peculiar forma de narrar consiste en la descripción psicológica de los personajes. A Stendhal (2000 [1840]: 724) no le interesaba el hecho histórico, sino que este era un pretexto para narrar al ser humano en sus pasiones, en sus amores, en sus miedos. Habla de la vida pero centrada en la persona, en su profunda individualidad, que no son más que sus emociones ${ }^{8}$. El medio (milieu) en que esa persona se desenvuelve es únicamente

6 Por ejemplo, Eric Auerbach en Mimesis. La representación de la realidad en la literatura occidental, 1942. Auerbach analiza las distintas manera de reproducir la realidad en Stendhal, Flaubert y Balzac.

7 Stendhal, en su respuesta a Balzac, reafirma la importancia de su estilo:"[...] je sui d'accord sur tout excepté sur le style. N'allez pas croire que ce soit excès d'orgueil. Je no vois qu'une règle: le style ne saurait être trop claire, trop simple. Les idées sur les profondeurs du cœur humaine étant inconnues aux enrichis, aux fats, etc., on ne saurait les énoncer trop clairement" (Stendhal, 2000 [1840]: 724).

8 Stendhal le explica a Balzac que el objeto de su novela es retratar el alma de sus personajes: "Je veux parler de ce qui se passe au fond de l'âme de Mosca, de la duchesse, de Clelia (Stendhal, 2000 [1840]:729). 
importante por la conexión que guarda con él. Por ese motivo, es comprensible que el escenario donde se desarrollan sus relatos sea secundario. Georges Blin (1973 [1954]: 108) Ilamó a esta técnica l'esthétique du miroir. Antes de Stendhal la descripción en las novelas francesas se basaba según los paradigmas naturalistas, postulados que narraban un objeto desde un punto de vista exterior, además de querer destacar lo pintoresco de las cosas, es decir, describir un objeto en su detalle mínimo. En estos casos, la visión narrativa se encontraba condicionada por la exterioridad. Stendhal hará lo contario, describirá el objeto a partir del sujeto (el personaje), subordinando la percepción, el campo de acción del narrador, a lo que el héroe del relato mira y le impresiona. De ahí que el valor de la cosa narrada ya no resida en elementos externos, sino en la psicología de los protagonistas. Por ello, Blin nombró a esta técnica estética del espejo, pues lo que el personaje mira (que es lo que relata el narrador) no es algo que está fuera de él. Más bien sucede que en su mirada se refleja a sí mismo, como el reflejo de su imagen frente al espejo.

Ahora bien, no hay que perder de vista que Stendhal tampoco es muy detallista en la descripción del relato psicológico9. La aridez con la que retrata la psiquis de sus héroes contiene la misma sequedad con la que describe sus paisajes, por lo cual cabe preguntarse en qué consiste específicamente el retrato psicológico. Balzac (1972 [1840]: 631) indica que Stendhal dibuja a sus personajes mediante la acción y el diálogo, e interrumpe las relaciones dramáticas entre estos a través de pequeñas sentencias o reflexiones. Si bien es cierto que así es, las intervenciones del autor10 son más evidentes en Le Rouge et le Noir (1830) que en La Chartreuse de Parme. En la parte final de Le Rouge et le Noir las intervenciones del autor son fundamentales para comprender el sentido moral de la historia, pero en La Chartreuse de Parme estas son más comedidas, o menos obvias para el lector. Por consiguiente, lo que realmente revela la psiquis de los protagonistas es la puesta de estos en una circunstancia determinada.

Stendhal dotará a todos sus personajes de intereses particulares. Así, tenemos que el fin de Gina es proteger a su sobrino Fabrice; Mosca pretende casarse con Gina; Fabio Conti quiere una vejez sin preocupaciones económicas; los príncipes Ranuce IV y V

9 Balzac criticó a Stendhal por la parquedad en el retrato de los personajes: "Les portraits sont courts" (Balzac, 1972 [1840]:631).

10 Georges Blin clasificó las intervenciones del autor en la obra de Stendhal en dos tipos: unas que modifican arbitrariamente la acción, el desarrollo de la intriga (du dedans), y otra en forma de voz activa que comenta y justifica los giros bruscos de los acontecimientos narrados (du dehors): "S'il y manque, il existe pour lui deux manières de se montrer. Il lui est loisible d'intervenir sois activement, du dedans, pour régler à sa guise, et dès lors arbitrairement, le développement de l'intrigue; soit du dehors: en prenant la parole des coulisses ou du trou du souffleur de manière à commenter des événements qu'il se défend de pouvoir modifier" (Blin, 1973 [1954]:180). Puede decirse que en La Chartreuse de Parme se utilizan más las intervenciones del tipo du dedans, aunque también hay intervenciones du dehors son menos frecuentes. 


\section{DE LA PRIMAVERA)}

desean acostarse con Gina, y Raversi se preocupa por conservar la herencia de su tío. Al mismo tiempo, el escritor creará coyunturas donde estos intereses se vean enfrentados. Tales circunstancias se iniciarán con el asesinato de Giletti a manos de Fabrice. Este hecho desencadenará una serie de eventos que propiciarán que todos los personajes se comporten en función de lo próximos que se encuentren de conseguir sus objetivos. Por lo tanto, la manera de mostrar la psicología de los personajes no es mediante la descripción directa de los protagonistas por parte de un narrador omnisciente, sino por la forma en que cada actor se comporta en la consecución de sus beneficios, es decir, la manera en que cada personaje actúa revela su esencia. Por ejemplo, el carácter calculador de Mosca se muestra cuando este, al saber que Gina está enamorada de su sobrino, en vez de dejarse llevar por los celos controla sus emociones, y lejos de hacerle daño, lo protege con el fin de mantenerse cerca de la duquesa Sanseverina. Lo mismo puede decirse de Gina, su falta de escrúpulos morales se ponen de manifiesto al acceder a tener relaciones sexuales con Ranuce $V$ para salvar la vida de Fabrice.

En resumen, Stendhal desarrolla el conflicto creando una infinidad de situaciones donde los intereses de todos los personajes de la novela se contraponen. Eso es lo que hace a La Chartreuse de Parme superior a Le Rouge et le Noir, ya que en esta novela las relaciones dramáticas se estructuran a partir de un único personaje, el héroe del relato. En cambio, en La Chartreuse de Parme las relaciones se extienden también a los demás personajes. Tal disposición provoca innumerables conflictos, lo cual conlleva buscar un desenlace para cada uno de ellos y no solo para el conflicto de Fabrice. También se hace necesario encontrar una salida para los demás implicados, de forma particular para Gina y Mosca. De manera que encontramos dos estructuras narrativas en el relato, una que se subordina a la historia de Fabrice y otra que se supedita a los demás personajes, que pueden agruparse bajo un solo tema: la corte de Parma. Aquí es donde reside el fallo estructural señalado por Balzac ${ }^{11}$. Si Stendhal pretende centrarse en Fabrice, la novela

11 Balzac le sugiere a Stendhal que si la novela se centra en Fabrice, esta debe ser más corta, por contra, si centra en todos los personajes es necesario que perfile mejor al héroe. Dependiendo del enfoque la novela será más o corta o más larga: "Mais si vous vouliez peindre toute la vie de Fabrice, vous deviez, vous homme si sagace, appeler votre libre «Fabrice, ou I'Italien au XXe siècle». Pour se lancer dans une pareille entreprise, Fabrice aurait dû ne pas se trouver primé par des figures aussi typiques, aussi poétiques que le sont les Princes, la Sanseverina, Mosca, Palla Ferrante. Fabrice aurait dû représenter le jeune italien de ce temps-ci. En faisant de ce jeune homme la principale figure du drame, l'auteur eût été obligé de lui donner une grande pensée, de le douer d'un sentiment qui le rendît supérieur aux gens de génie qui l'entouraient et qui lui manque. En effet, le sentiment est égal au talent. Sentir est le rival de Comprendre, comme Agir est l'antagonisme de Penser. L'ami d'un homme de génie peut s'élever jusqu'à lui par l'affection, par la compréhension. Sur le terrain du cœur, un homme médiocre peut l'emporter sur le plus grand artiste. Là est la justification des femmes qui aiment des imbéciles. Ainsi, dans un drame, unes de ressources les plus ingénieuses de l'artiste est (dans le cas où nous supposons M. Beyle), de rendre supérieur par le sentiment un héros qui ne peut lutter par le génie avec les personnages qui l'entourent. Sous ce rapport, le rôle de 
debería ser más corta, incluso tendría que cambiarle el título, pues La Chartreuse de Parme evoca un argumento distinto. También sería indispensable suprimir la complejidad de los demás protagonistas, lo cual significa que deben estar diseñados en función de la problemática del héroe y no presentar conflictos propios. La otra solución sugerida por Balzac (1972 [1840]: 630) es hacer más extensa la novela para explayarse aún más en el conflicto y desenlace del resto de actantes. En ese caso la estructura principal giraría en torno a las intrigas que suceden en la monarquía de Parma, siendo Fabrice un personaje más de todo el elenco que integran el reino parmesano.

Si en la novela de Stendhal el drama desborda al argumento, en Carpentier sucede lo contrario, sus relatos carecen de dramatismo porque apenas construye personajes. La consagración de la primavera es interesante porque tiene el potencial para ser un relato dramático, pero Carpentier evita desarrollar las relaciones dramáticas ubicando el conflicto en la forma singular de exponer la narración. Tal particularidad consiste en que el orden causal de los hechos narrados (la fábula) difiere de argumento del relato (la trama). Mientras la fábula nos cuenta la historia de amor de Enrique y Vera, la trama nos presenta otro tema: las relaciones que se establecen entre el intelectual y la realidad, realidad que se simboliza en las convulsiones políticas y sociales, concretamente en las revoluciones.

A pesar de la existencia de dos temáticas (una historia de amor y las relaciones entre el intelectual y la política), eso no significa que la novela tenga dos estructuras. Ocurre que hay dos niveles diferenciados de lectura: en el nivel inferior se encuentra el asunto amoroso y en el nivel superior se desarrolla la idea filosófica del autor. Con ello, el escritor cubano desplaza el asunto amoroso a una importancia menor, mientras que el tema filosófico acapara la atención del lector.

Parallevara cabo este procedimientoes fundamental la presentación del relato, porque el autor dispone los hechos de manera diferente a cómo suceden cronológicamente. La narración se inicia a mitad de la fábula, cuando cada protagonista se encuentra en un pueblo de Valencia, aunque la historia personal de cada uno comienza antes, contándose dichos episodios en forma de retrospecciones o analepsis ${ }^{12}$ (ver esquema 3 ); lo cual le permite al escritor no subordinar la intriga de la novela a las relaciones dramáticas entre Vera y Enrique, pues lo que se está contando es la vida de cada uno de ellos, haciendo que el conflicto que surge entre ambos sea solo un problema más de los tantos que les suceden en el transcurso de sus existencias. Dicho de otra manera, el conflicto no se origina a partir de los problemas de los amantes, sino entre cada uno de los personajes

Fabrice exigerait une refonte [...] L'ouvrage doit donc être ou plus court ou plus long" (Balzac, 1972 [1840]: 630).

12 Gerard Genette define la analepsis de la siguiente manera: "[...] toda evocación posterior de un acontecimiento anterior al punto de la historia donde nos encontramos" (Genette, 1989 [1972]: 95). 
y la vida; vida que Carpentier simboliza a través de ciertos eventos históricos y políticos, cuyas características son sus naturalezas revolucionarias y repetitivas (cíclicas).

El segundo aspecto que a Carpentier le facilita la configuración de este tipo de conflicto es el uso del tiempo y la voz narrativa. La novela está narrada en primera persona. La instancia narrativa se reparte entre los dos personajes principales. La técnica con que se desarrolla la narración es el soliloquio o monólogo citado ${ }^{13}$ y no tanto el stream of consciousness, porque si bien es cierto que la narración evoca los pensamientos de los personajes, estos nunca llegan a ser incoherentes, por lo que no es una auténtica corriente inconexa de pensamientos, más bien lo que encontramos es la referencia directa a los pensamientos de los personajes sin ninguna mediación. Por otro lado, en otras partes del texto Carpentier se auxilia de puntos suspensivos que tienen la función de omitir una secuencia narrativa, lo que indica que el narrador está deteniendo el soliloquio ${ }^{14}$. Al mismo tiempo, el uso de los puntos suspensivos le permite a Carpentier imitar la oralidad en la escritura (aunque eso no implica que logre una auténtica escritura oral ${ }^{15}$ ). De esta manera el uso del soliloquio y el empleo de puntos suspensivos le permiten establecer una conexión entre el narrador y el tiempo.

La proximidad del relato a la oratoria posibilita que el lector sea partícipe del pensamiento de los protagonistas, no de su cronología, pues no existe una auténtica exposición en la novela, como tampoco encontramos una verdadera intriga. El relato no posee un principio, un nudo y un desenlace, son pensamientos que se encuentran más

13 Estébanez Calderón explica que el soliloquio consiste en "una «transcripción directa» de contenidos de la conciencia analizados de manera lógica por un personaje, en forma de autoanálisis o de confesión, lo que implica cierta relación dialógica consigo mismo o con un imaginado o supuesto receptor"(Estébanez, 1996 [2008]: 692).

14 El siguiente fragmento muestra cómo funciona el monólogo citado y los puntos suspensivos en Carpentier: "Era judía, y orgullosa de serlo, aunque no practicante: "Veo las esencias del judaísmo como una maravillosa herencia. Nada me conmueve tanto como el canto de las sinagogas. Pero no tengo la fe que requiere la honesta observancia de un ritual. Un ritual no folklore. Responde a un sentido religioso que no tengo. $\mathrm{Si}$, por dar gusto a mis padres, observara ciertas prácticas, haría trampa"... Muy dotada para el piano, desde la niñez, había tenido que abandonar sus adolescentes afanes de concertista a causa de un accidente que había quitado toda agilidad al dedo medio de una mano izquierda [...]" (Carpentier, 2004 [1978]: 104). Aquello que se narra dentro de las comillas, antes de los puntos suspensivos, ocurre dentro del pensamiento del personaje, mientras lo que sucede después, es la narración de los eventos que constituyen el objetivo del subcapítulo.

15 Carpentier no consigue una genuina escritura oral porque evita el uso de coloquialismos propios del lenguaje popular. Precisamente, una de las críticas negativas que Roberto González hizo a la novela fue que el habla de los personajes no se corresponde al idioma común de los cubanos: "Proliferan voces que no son del uso común de cubanos, como «bragas», por ejemplo, y diminutivos en «illo». ¿Qué cubano diría jamás «mancuernas» al hablar de yugos y gemelos? [...] En boca de personajes contemporáneos y cubanos, la falsedad de los diálogos de Carpentier es irritante" (González, 2004 [1993]: 352). 
allá del tiempo representado en el relato ${ }^{16}$. Esto facilita que las analepsis se presenten sin aviso, impidiendo identificar marcas literarias que señalen al lector los saltos en el tiempo. Carpentier introduce el pasado sin anunciarlo, y el recurso es válido en tanto que el escritor no quiere contarnos la historia de amor entre Vera y Enrique (que implicaría representar el tiempo de la fábula), sino que nos presenta sus pensamientos, que no tienen por qué subordinarse a las categorías temporales de la narración. En síntesis, Carpentier no se vale de pasajes introductorios para realizar cambios en el tiempo, y lo hace gracias al uso del monólogo, que impone al lector leer el texto como una diatriba y no como un relato.

En conclusión, para evitar las relaciones dramáticas entre los personajes, Carpentier se centra en la manera de mostrar el relato, es decir, su genio narrativo radica en los aspectos formales y no en el contenido de la ficción. A diferencia de La Chartreuse de Parme, la novela de Carpentier está bien hecha estructuralmente. El problema reside en el concepto que se tiene de la novela, en especial en la noción de conflicto narrativo.

Es evidente que la intención de Carpentier es mostrar lo problemáticas que son las relaciones entre el intelectual y la realidad política (las revoluciones), pero este es un tema demasiado abstracto. Para contar un relato se necesita una situación específica, para lo cual Carpentier construye el conflicto a partir de la relación amorosa entre Vera y Enrique, pero su negativa a profundizar en las relaciones psicológicas entre ellos provoca que el conflicto sea un drama de poca complejidad (Vera abandona a Enrique porque este tiene relaciones sexuales con su prima). Por otro lado, tal situación ocurre casi al finalizar la novela (en el capítulo VI), lo que significa la lectura de cinco capítulos que únicamente tienen la función de configurar a los personajes, mas donde no sucede nada. Paradójicamente, Carpentier tiene las mismas dificultades que Stendhal con La Chartreuse de Parme, pues los primeros episodios de esta novela solo sirven para desarrollar al personaje de Fabrice. La diferencia radica en que Carpentier es muy hábil en el empleo -y la exhibición- de artificios literarios, no así Stendhal (2000, [1840]: 733), que se negó a utilizarlos. Los efectos literarios de La consagración de la primavera permiten que su lectura sea más interesante. El fallo es no usar el lenguaje popular, oral, lo que provoca que no se diferencie la voz narrativa de Vera y Enrique, creando un único registro literario. Además, la negativa a profundizar en la psicología de ellos ocasiona que en la

16 El tiempo que predomina en el relato es lo que Todorov llama tiempo de la escritura: "Junto a la temporalidad del enunciado, existe también una temporalidad de la enunciación formada por la concatenación de las «instancias del discurso», es decir, de las coordenadas temporales que el discurso provee acerca de su propia enunciación; esta instancia misma es la que define el tiempo presente como tiempo de la enunciación; la obra que obedece a esta temporalidad podemos denominarla el «tiempo de la escritura», por oposición al tiempo representado" (Todorov 2004 [1968]: 114-115). 


\section{DE LA PRIMAVERA)}

práctica no existan dos personajes, sino uno solo. Si a ello le sumamos que al conflicto le falta complejidad, puede decirse que La consagración de la primavera es un monólogo que aspira a ser una novela épica.

Así pues, Carpentier y Stendhal presentan retos diferentes en el desarrollo de sus narrativas. Al rechazar Carpentier la creación de personajes y situaciones dramáticas el conflicto carece de profundidad, pero dado que se enfrenta al reto de crear un novela de gran formato, traslada su genio creativo a la manera de contar la historia. Ahí radica su talento. Stendhal, en cambio, aspira a desarrollar personajes y, sobre todo, a situarlos dentro de una circunstancia, por lo que la configuración de un conflicto es fundamental en su escritura. Sin embargo, es en esta cuestión donde encuentra su mayor dificultad, ya que tiene que buscar un equilibrio para que el conflicto no sature la manera de narrar, que es precisamente en lo que Carpentier se especializa. Dicho de otra manera, la fortaleza de Carpentier (la enunciación de la narración) constituye la debilidad de Stendhal, en tanto que la creación de personajes y situaciones es la agudeza del escritor francés, no así la del cubano, cuyos textos exigen que se lean de forma no tradicional.

\section{ORDEN EN LA ORGANIZACIÓN DEL TEXTO}

A pesar de que en La Chartreuse de Parme los eventos se narran cronológicamente, se tiene la impresión de que el orden en la organización textual es espacial ${ }^{17}$, siendo aparentemente- el objeto de la narración la evocación de un espacio. Esto ocurre porque el conflicto de la novela (el asesinato de Giletti) se produce tarde, en el capítulo once (ver esquema 1). Todos los capítulos anteriores están ligados por nexos sin causalidad, por lo que no es posible saber por dónde se va a desarrollar la historia. Además, el conflicto del relato no se limita al homicidio de Giletti, se extiende al resto de personajes. Todos ellos tienen sus propias pugnas al margen del conflicto principal, generando pequeñas intrigas que rivalizan con la intriga mayor, haciendo que la novela adquiera dimensiones gigantescas. Finalmente, el aspecto que desconcierta es el título de la novela. La Cartuja de Parma aparece únicamente al principio y al final del relato, es el lugar en que el narrador conoce la historia de Gina y adonde se encierra Fabrice a esperar la muerte. En este caso, el título no indica sobre qué trata la novela, atañe más bien al conflicto del héroe, su deseo de llevar una vida diferente a la que ha sido sometido -por su tía y por el conde Mosca-, pues se le ha impuesto una existencia en la que impera el valor de lo material en menoscabo de lo espiritual. Después de muchos intentos desesperados por llevar una vida según sus propias normas, pero cuyos planes se ven frustrados constantemente, Fabrice no encuentra motivos para continuar viviendo, y se encierra en

17 Por ejemplo, para el filólogo alemán Wolfang Kayser, La Chartreuse de Parme es una clara novela de espacios: "La Chartreuse de Parme se inclina ya claramente a la novela de espacio" (Kayser, 1992 [1954]:488). 
la Cartuja porque no quiere saber nada del mundo. Así pues, el título de la novela remite al conflicto psicológico del héroe y no a los eventos que la novela narra. Todas estas circunstancias hacen pensar que no se cuenta ningún conflicto, sino que se trata del relato de un ambiente. No obstante, hay un asunto que se desarrolla cronológicamente y que es preciso solucionar: la culpabilidad o inocencia de Fabrice del asesinato de Giletti. Por lo tanto, sí existe una cronología, un relato.

Ahora bien, dentro de ese orden los hechos que giran alrededor del juicio de Fabrice son causales, no así los demás sucesos, que se encuentran unidos por vínculos sin causalidad interna (temporales-ideológicos), concebidos solamente para describir al héroe. El siguiente esquema muestra los eventos enlazados por la causalidad y aquéllos carente de ella ${ }^{18}$.

Esquema 1. Conexión de los eventos en La Chartreuse de Parme

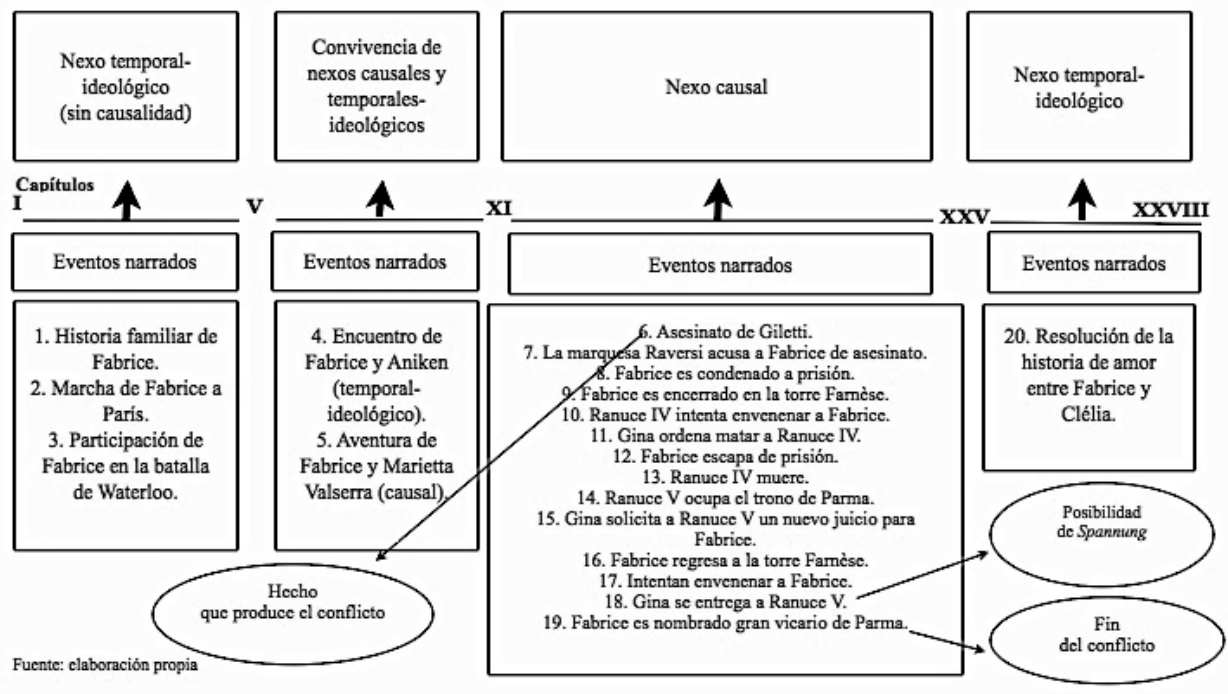

Puede observarse que los acontecimientos que se agrupan alrededor del juicio de Fabrice (del capítulo XI al XXV) están vinculados únicamente por nexos causales,

18 Algunos acontecimientos del esquema se han sintetizado bajo un tema. Es el caso del evento veinte (resolución de la historia de amor entre Fabrice y Clélia). Este hecho está formado por otros sucesos causales (casamiento de Clélia y Crescenzi, partida de Mosca y Gina, embarazo de Clélia, muerte de Sandrino, etcétera). Pero se ha clasificado como temporal-ideológico por la manera en que se relaciona con el conflicto principal (el homicidio de Giletti), puesto que no existe un vínculo lógico causal con tal incidente. De ahí que se establezca que todas estas acciones tienen la función de finalizar la historia de Fabrice, que al carecer de conflicto (debido a que Fabrice deja de tener un rol dinámico en el homicidio de Giletti), se transforman en un grupo de acciones cuyo papel primordial es la descripción de la personalidad del héroe. 


\section{DE LA PRIMAVERA)}

mientras que los otros se relacionan, en su mayoría, por nexos temporales-ideológicos, cuya función es exponer la personalidad de Fabrice. Este tipo de acontecimientos podrían sintetizarse, ya que no aportan nada al conflicto de la fábula, de manera que la novela bien podría estructurarse solo con los eventos enlazados causalmente. Tendría que finalizar en el capítulo XXV y no extenderse tres capítulos más, pues tal extensión provoca que no se logre lo que algunos Ilaman Spannung ${ }^{19}$. Efectivamente, el momento más tenso, y que es anterior a la resolución del conflicto, se produce cuando Gina accede a tener sexo con Ranuce $V$ (en el esquema 1 se visualiza cómo este hecho precede el final del conflicto). Tal situación permite la exculpación de Fabrice y su nombramiento como futuro sucesor del arzobispo de Parma. Al mismo tiempo escenifica la victoria de Gina sobre sus enemigos políticos. Con ello finaliza el conflicto de la novela (el homicidio de Giletti a manos de Fabrice), pero no queda solucionada la idea filosófica que Stendhal pretende introducir: la relación entre la modernidad y las emociones, y que procedemos a explicar a continuación.

Stendhal caracterizó la modernidad como una vida vacía y superflua. Para entender esta idea es fundamental mencionar el pasaje de Le Rouge et le Noir en el que Julien Sorel se encuentra con el príncipe ruso Korasoff. Julien le comparte sus desdichas amorosas, ante lo que Korasoff le da un consejo: debe ser un hombre más ligero, menos reflexivo y trascendente:

C'était le prince Korasoff, cet ami de Londres, qui lui avait dévoilé quelques mois auparavant les premières règles de la haute fatuité [...] Vous avez la mine d'un trappiste, dit-il à Julien, vous outrez le principe de la gravité que je vous ai donné à Londres. L'air triste ne peut être de bon ton; c'est l'air ennuyé qu'il faut. Si vous êtes triste, c'est donc quelque chose qui vous manque, quelque chose qui ne vous a pas réussi. C'est montrer soi inférieur. Etes-vous ennuyé, au contraire, c'est ce qui a essayé vainement de vous plaire qui est inférieur. Comprenez donc, mon cher, combien la méprise est grave (Stendhal, 1958 [1830]: 398-399).

El principe de la gravité representa que no hay que buscar significado a (o en) la vida moderna, porque no la tiene. La modernidad carece de trascendencia, si se quiere vivir -y sobre todo triunfar socialmente- hay que dejarse llevar por el funcionamiento social y, en especial, hay que abstenerse de cuestionar las reglas sociales, porque la única intención que tienen es la operatividad de la sociedad y no mejorarla el sentido humanístico. La misma idea se repite en La Chartreuse de Parme. Gina le da un consejo a Fabrice para

19 Término de origen alemán introducido por Tomachevski (1982 [1928]: 185) que indica la tensión previa a la finalización del conflicto. 
que pueda sobrevivir y triunfar en la Corte: no debe cuestionar las reglas del juego de los salones, lo que tiene que hacer es aprender a jugar: "Crois o ne crois pas à ce qu'on t'enseignera, mais ne fais jamais aucune objection. Figure-toi qu'on t'enseigne les règles du jeu de whist; est-ce que tu ferais des objections aux règles du whist?" (Stendhal, 2000 [1839]: 179). No hay mejor figura que comparar el funcionamiento de la sociedad moderna con un juego, así se extirpa de la vida social todo signo de trascendencia. Además, entender la vida social como un juego implica que el ser humano debe abandonar todo anhelo de trascendencia y buscar la manera de encajar, pues es más importante funcionar que ser. Y ser moderno supone ser liviano. La diferencia entre liviano y pesado, superfluo y complejo no es algo que tenga que ver con la erudición, ni con la sapiencia intelectual. Ser complejo es vivir la vida según las pasiones y las emociones pero siendo muy consciente de ellas, en cambio, ser liviano significa no reflexionar acerca de los sentimientos, simplemente dejarse llevar por éstos.

Podría decirse que la filosofía de Stendhal se opone a la intrascendencia consecuencia de la modernidad, el elogio a las pasiones en sus novelas es una estrategia de resistencia a esta; e introduce esta ideología a través del personaje principa ${ }^{20}$. Los primeros acontecimientos narrados en La Chartreuse de Parme (la historia familiar de Fabrice y su marcha a París) sirven para mostrar la personalidad del héroe: un joven que tiene la voluntad de encontrarle un significado a la vida. Tal búsqueda le lleva a participar en la batalla de Waterloo. A pesar de que se marcha convencido de que su participación será decisiva para el triunfo de los suyos -y llenarse de gloria ${ }^{21}-$, se da cuenta de que su presencia en la batalla es insignificante; también comprende que la guerra no tiene nada de hermosa ni de heroica, únicamente son sucesos caóticos y carentes de significación. La importancia del pasaje no radica en la descripción realista de lo qué es una batalla, su significado es filosófico. El héroe aprende que en la vida no existe nada trascendente, y es entonces cuando decide otorgarle otra medida de valor a la existencia: las pasiones. A partir de ese momento Fabrice transitará por el mundo buscando algo que le haga sentir. Creerá encontrarlo en su relación con Clélia, pero el trágico final le priva de tal experiencia. Como el mundo ya no le puede ofrecer nada, se retira a morir a una cartuja.

20 Este es el motivo por el que todos los episodios concernientes a la representación de Fabrice sean calificados como temporales-ideológicos, pues muestran la idea filosófica de Stendhal.

21 Según Michel Crouzet, la gloria (literaria y militar) para Stendhal equivale a la posterioridad: "[...] la gloire est romantique parce qu'elle est un énergétique de la générosité, l'écrivain et le conquérant sont identiquement des «amants de la gloire» [...] Mais qu'est-ce que la gloire? Je crains que cette notion, qui est au centre du romantisme, ne soit incompréhensible à nos contemporains: la modernité sacrifie le présent à l'avenir où elle se projette en tout instant, mais elle ne convie pas les modernes à subordonner leur vie à une survie terrestre, à sacrifier leur existence à une existence dans la postérité, à une existence morale dans le souvenir des hommes" (Crouzet, 2010: 96, 100). 
Se aprecia que la novela presenta dos tramas (y dos héroes). Una que corresponde al drama de Fabrice (donde el héroe es él mismo), y otra que se circunscribe al asesinato de Giletti (donde la heroína es Gina). Los eventos unidos por nexos temporales-ideológicos corresponden al argumento de Fabrice, en tanto los hechos enlazados por relaciones causales competen al asesinato de Giletti. La trama de Fabrice carece de conflicto, porque probablemente el crimen de Giletti pretendía serlo, mas la complejidad de tales eventos hace de estos hechos un relato autónomo, dejando el argumento original sin conflicto. En ello tiene que ver la profundidad psicológica de los personajes que, en principio, debían ser secundarios. Gina termina siendo la protagonista de la estructura narrativa que se refiere a la muerte de Giletti, puesto que tiene un papel más activo que el supuesto héroe. La solución propuesta por Balzac (1972 [1840]:630) era acertada. Stendhal tenía dos alternativas, rebajar el nivel de los personajes secundarios, dándole mayor dinamismo a Fabrice y logrando así que el homicidio de Giletti se encadene causalmente a la estructura principal de la novela, o bien reducir los fragmentos temporales-ideológicos haciendo de Fabrice un personaje más de todo el elenco actoral.

La negativa de Stendhal a hacerlo revela su auténtica intención. El escritor estaba más interesado en introducir y hacer valer su idea filosófica que en narrar claramente un relato ${ }^{22}$. En consecuencia, el principio que rige la organización del texto no proviene de la lógica causal de los eventos narrados, sino por el arbitrio del escritor (son las intervenciones del autor que Blin (1973 [1954]: 180) llama du dedans ${ }^{23}$ ). Es decir, La Chartreuse de Parme es una narración ideológica, porque impera más el designio del escritor (mostrar su visión de mundo) que el orden causal de los hechos contados.

Al igual que La Chartreuse de Parme, La consagración de la primavera no es una novela de espacios, sino que narra un conflicto amoroso: la relación entre Vera y Enrique, que se ve en peligro porque este se acuesta con su prima Teresa. Por lo tanto, puede decirse que en el texto existe un relato. Ahora bien, los vínculos que predominan en el enlace de acontecimientos son temporales-ideológicos. El siguiente esquema permite visualizarlo mejor. Téngase en cuenta que la fábula (la exposición de los hechos según el orden cronológico) es diferente a la trama (la exposición de los acontecimientos según el narrador), por lo que encontramos dos niveles de lectura, aunque, como ya se ha mencionado, solo hay una estructura. Mostraremos en primer lugar los eventos según

22 Stendhal se miraba como un pensador que utilizaba la literatura para introducir sus ideas. Esta afirmación puede deducirse de sus modelos literarios: François de Salignac de La Mothe (Fénelon) (teólogo y filósofo, autor de Les Aventures de Télémaque, 1699) y Charles-Louis de Secondat, barón de Montesquieu (filósofo político, autor De l'esprit des lois, 1748): "Les seuls auteurs qui me fassent l'effet de bien écrire, c'est Fénelon: Les Dialogues des morts, et Montesquieu" (Stendhal, 2000 [1840]: 729).

Ver nota de pie número 10. 
el orden cronológico, y más adelante presentaremos los hechos tal y como los narra el escritor.

\begin{tabular}{|c|c|c|}
\hline \multicolumn{2}{|c|}{ Eventos narrados (nexos causales y temporales-ideológicos) } & \\
\hline $\begin{array}{l}\text { 1. Enrique parte de Cuba (temporal-ideológico). } \\
\text { 2. Vera y su familia huye de Baku (temporal- } \\
\text { ideológico). } \\
\text { 3. Enrique se instala en México (temporal-ideológico). } \\
\text { 4. Vera se muda a Londres (temporal-ideológico). } \\
\text { 5. Enrique se traslada a París (temporal-ideológico). } \\
\text { 6. Vera se traslada a París (temporal-ideológico). } \\
\text { 7. Enrique se enamora de Ade (temporal-ideológico). } \\
\text { 8. Vera se enamora de Jean-Claude (temporal- } \\
\text { ideológico). } \\
\text { 9. Ada abandona a Enrique (temporal-ideológico). } \\
\text { 10. Jean-Claude abandona a Vera (temporal- } \\
\text { ideológico). } \\
\text { 11. Enrique se marcha a Berlin (temporal-ideológico). } \\
\text { 12. Vera se marcha a Valencia (temporal-ideológico). } \\
\text { 13. Enrique regresa a París (temporal-ideológico). } \\
\text { 14. Enrique se marcha a España } \\
\text { (temporal-ideológioo). } \\
\text { 15. Enrique conoce a Vera (causal) } \\
\text { 16. Enrique y Jean-Claude parten al frente de guerra } \\
\text { (temporal-ideológico). } \\
\text { 17 Vera recibe la noticia de la muerte de Jean-Claude } \\
\text { (temporal-ideológico). }\end{array}$ & $\begin{array}{l}\text { 18. Enrique y Vera se convierten en amantes (causal). } \\
\text { 19. Enrique y Vera se trasladan a La Habana (temporal-ideológico) } \\
\text { 20. Vera decide montar una escuela dedanza (temporal-ideológico). } \\
\text { 21. Enrique tiene sexo con Teresa (causal) } \\
\text { 22. Vera representa el Carnaval de Schumann (temporal-ideológico). } \\
\text { 23. Vera se propone representar La consagración de la primavera de Stranvinski } \\
\text { (temporal-ideológico). } \\
\text { 24.Vera busca financiación para representar La consagración de la primavera de } \\
\text { Stranvinski (temporal-ideológico). } \\
\text { 25. Enrique ayuda a un amigo que participa en un atentado contra Batista } \\
\text { (temporal-ideológico). } \\
\text { 26. Enrique abandona Cuba (temporal-ideológico). } \\
\text { 27.Asesinato de tres estudiantes de Vera (temporal-ideológico) } \\
\text { 28. La policía acusa a Vera de guardar material revolucionario } \\
\text { (temporal-ideológico). } \\
\text { 29. La tía de Enrique habla con Batista para proteger a Vera (temporal- } \\
\text { ideológico). } \\
\text { 30. La tía de Enrique ordena a Vera cerrar la escuela de danza (temporal- } \\
\text { ideológico). } \\
\text { 31. Teresa le cuenta a Vera que cs amante de Enrique (causal) } \\
\text { 32. Vera se marcha a Baracoa (causal). } \\
\text { 33. Triunfo de la revolución de Fidel Castro (temporal-ideológico). } \\
\text { 34. Enrique regresa a Cuba (temporal-ideológico). } \\
\text { 35. Enrique se incorpora a las milicias armadas (temporal-ideológico). } \\
\text { 36. Enrique es herido en la batalla de Playa Girón (temporal-ideológico). } \\
\text { 37 Vera regresa con Enrique (temporal-ideológica) } \\
\text { 38. Vera planea la representación de La consagración de la primavera (temporal- } \\
\text { ideológico). }\end{array}$ & \\
\hline
\end{tabular}

Puede distinguirse que de treinta y ocho eventos únicamente cinco son causales - y son ellos los que sostienen la novela-, los cuales son: Enrique conoce a Vera (1), Enrique y Vera se convierten en amantes (2), Enrique tiene sexo con Teresa (3), Teresa le cuenta a Vera que Enrique es su amante (4) y Vera se marcha a Baracoa (5). Las acciones 1 y 2 pueden agruparse en un solo evento, que sería la situación original del relato (en el drama clásico se conoce como prótasis ${ }^{24}$ ); las acciones 3 y 4 también pueden unificarse en un solo acontecimiento, que sería la aparición del conflicto (epítasis ${ }^{25}$ ); y el evento 5 constituiría el momento en que se retarda la solución al conflicto (catástasis ${ }^{26}$ ). Faltaría el desenlace, la vuelta a la situación original. Puede argumentarse que este es el regreso de Vera con Enrique (esquema 2, acción 37), no obstante, lo hemos clasificado como temporal-ideológico y no causal, ya que en él no se narra la causa por la que Vera regresa

24 Estébanez Calderón define la prótasis como una fase de la acción dramática: "La acción dramática se desarrolla en tres fases: prótasis o planteamiento, epítasis o tensión, y catástrofe o desenlace (...) Es la parte central de la acción dramática, en la que sobrevienen los acontecimientos de mayor trascendencia y se intensifican los conflictos, que constituyen el «nudo» de la trama. En el desenvolvimiento de dicha trama, detrás de la prótasis (que era la primera parte, expositiva de presentación) venía la epítasis, a la que sucedía el paréntesis dilatorio de la catástasis, y, finalmente, la catástrofe, cuando la acción llega a su término y el héroe sufre las consecuencias trágicas de su hamartia o error fatal" (Estébanez, 1996 [2008]: 346, 1048).

Ver nota del pie número 24. 
con Enrique. Entre la partida de Vera a Baracoa y su regreso con Enrique falta una acción (o varias acciones) que sea producto de los eventos anteriores, y pueda así establecerse un bloque de hechos vinculados por relaciones causales. Esto nos indica que el relato no tiene un desenlace que sea consecuencia de un evento anterior, situación que ocasiona que La consagración de la primavera sea una novela sin conflicto dramático.

Es evidente que Carpentier no desea desarrollar un drama, de ahí que se auxilie de otro tipo de conflicto: la relación entre el héroe y su medio, que en la novela se simboliza a través de las relaciones entre el intelectual-artista con las revoluciones. El conflicto se identifica mejor al visualizar la trama, que esquematizamos del siguiente modo:

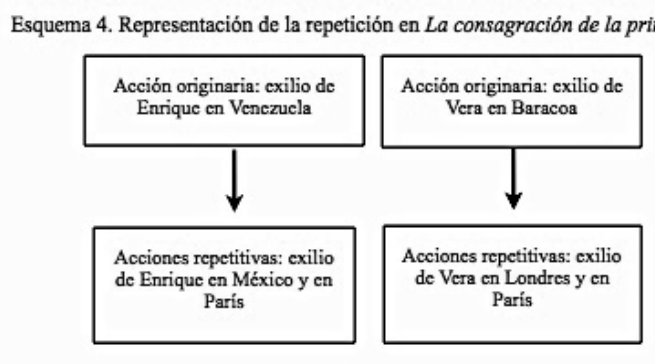

Fuente: elaboración propia

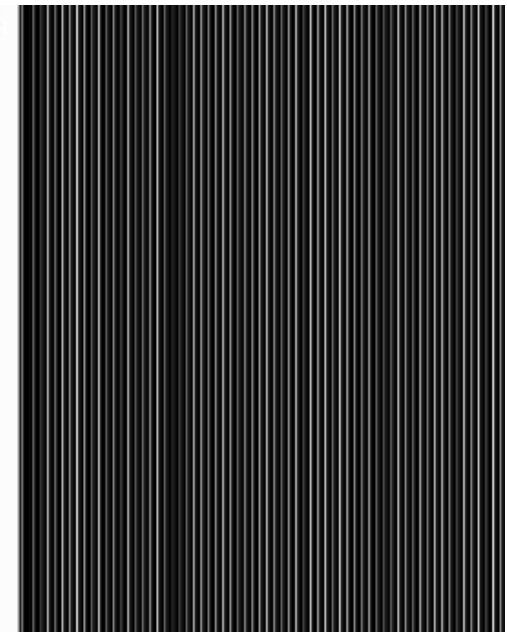

Al examinar la manera en que Carpentier ordena los eventos narrados nos damos cuenta que el pasado amoroso de los protagonistas, así como sus respectivas migraciones ya no son importantes para el relato, solo forman parte de la biografía de los héroes (razón por la que no se han tipificado como sucesos causales). Incluso, en este nivel, el problema de Enrique y Vera deja de ser esencial para la ficción, pues tales hechos vendrían a sumarse a sus semblanzas. Por tanto, el conflicto se desplaza a la ayuda que Enrique presta a un amigo que participó en un atentado contra Batista, y el asesinato de tres estudiantes de Vera. Ambos hechos están vinculados con las convulsiones sociales y políticas de Cuba (las revoluciones), encarnando el conflicto de la trama.

Enrique participa de manera indirecta en el golpe frustrado contra Batista. Se trata de una participación malograda, no solo históricamente, sino en la trayectoria del héroe, pues el miedo le obliga a exiliarse en Venezuela. Y es que la actitud inicial de los protagonistas frente a las revueltas sociales es siempre la huida. En el caso de Enrique la necesidad de escapar obedece a su relación vacilante entre él mismo y los movimientos sociales, entre la realidad política y el compromiso del intelectual, circunstancia que se 
simboliza en el auxilio que presta a su amigo revolucionario. En lo que respecta a Vera, la intriga se materializa en escapar de su implicación con los tres estudiantes asesinados. Lo hace pidiendo ayuda a Teresa y a la tía de Enrique. Así pues, estos episodios constituyen el conflicto y la intriga de la novela, cuya resolución vendría a ser la participación de Enrique en la batalla de Playa Girón, y el regreso de Vera a La Habana.

La implicación de Enrique en la batalla de Playa Girón constituye el desenlace del conflicto. Después de huir de los problemas sociales y políticos de Cuba, su intervención en el combate representa su fe en las revoluciones. Contrariamente, el regreso de Vera a La Habana es una forma resignada de someterse a los eventos políticos, que a fin de cuentas son los que conducen su vida, es decir, la realidad política termina por imponerse a la voluntad de Vera. En resumen, el conflicto se resuelve mediante la fe en las revoluciones por parte de Enrique, y en la resignación a estas en el caso de Vera. Si leemos la novela en clave dramática el relato queda acéfalo, mientras si lo hacemos en el nivel que hemos presentado la novela se muestra acabada: contiene un inicio (la huida de los héroes de la realidad política), un conflicto (la confrontación de los héroes con la realidad política) y un desenlace (la implicación de los héroes con la realidad política).

En consecuencia, el principio que ordena los eventos narrados es temporal-ideológico, porque el escritor necesita introducir una idea ajena a los hechos causales para configurar el conflicto. Esto le permite a Carpentier orientar la historia en otro sentido, creando otro nivel de lectura $y$, por supuesto, configurando otro tipo de conflicto. Pero los eventos temporales-ideológicos no tienen únicamente la función de dirigir el conflicto de la novela a otro nivel, el escritor también introduce una idea filosófica mediante los mismos. Tal idea es que la vida es una sucesión de momentos que se repiten, existiendo un destino así como una fatalidad. Las revoluciones -como partes de la vida- vendrían a ser cíclicas. Escapar de ellas es imposible, no es opción para el intelectual. A continuación mostramos cómo incrusta Carpentier su filosofía en el texto.

Existen ciertos pasajes en La consagración de la primavera que son repeticiones de otras escenas. El siguiente esquema muestra la acción originaria junto con sus respectivas replicas ${ }^{27}$ :

27 Para comprender mejor la idea de la repetición es necesario no visualizar los eventos de la novela de forma cronológica, es decir, debe leerse a partir de la trama y no de la fábula. 
Esquema 4. Representación de la repetición en La consagración de la primavera

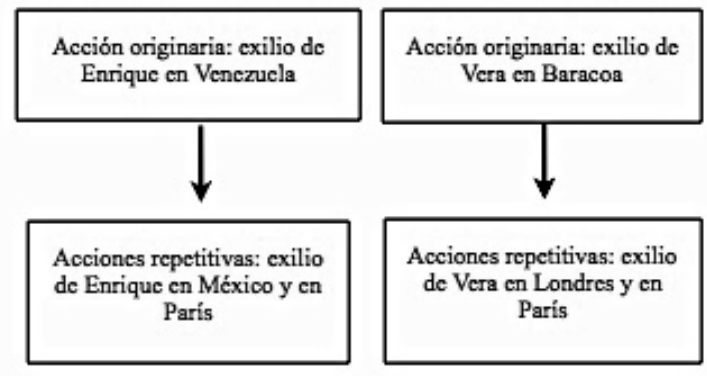

Fuente: claboración propia

El exilio es la acción principal de las escenas anteriormente citadas. Este es producto de un evento político que altera la trayectoria de los protagonistas, obligándoles a emigrar. La acción de los dos fragmentos originarios es la misma: los eventos políticos contra Batista. Por otra parte, la partida de Enrique a México se debe a la represión social de Machado, y el destierro de Vera es producto de la Revolución bolchevique. Estos exilios los conducen a París, luego a La Habana, consecuencia también del estallido de la Segunda Guerra Mundial. En tales eventos ya no solo se produce la repetición de los hechos, sino que se introduce la idea del destino y la circularidad. La expulsión de los héroes de sus respectivos países los lleva a París, ciudad donde se convierten en amantes. Con este episodio Carpentier fundamenta la idea de que ambos protagonistas estaban destinados a encontrarse, a pesar de que los dos nacen en lugares distantes: Bakú y La Habana. La igualdad de experiencias (los exilios) provocan la sensación en el lector de que en algún momento ambos tiene que coincidir en un mismo lugar y tiempo. En cuanto a la circularidad, ésta se expresa mejor en la vida de Enrique: de La Habana parte a México, después a París y posteriormente regresa a La Habana, de modo que su vida se convierte en un viaje circular ${ }^{28}$. Asimismo, las revoluciones o eventos políticos que cada protagonista tiene que vivir, ya sea de forma separada o conjunta, refuerza la idea de fatalidad. Los sucesos históricos que aparecen en la novela no tienen únicamente una conexión con los protagonistas, están relacionadas entre sí, como parte de un mismo sino.

En conclusión, tanto la novela de Stendhal como la de Carpentier son ideológicas, lo cual significa que para ellos es más importante expresar sus ideas acerca del mundo que comunicar claramente una historia, por lo que la literatura es un medio y no un fin en sus escrituras. De ahí el error en lo que concierne a la configuración de sus respectivas tramas, aunque las causas de los equívocos en cada escritor obedezcan a motivos

28 La circularidad en Vera se refleja de otra manera. La novela se inicia y finaliza con el mismo pensamiento de Vera: "Cayó la noche, se fueron los dos, y 1, 2, 3, 1 yyyý 2 yyyý 3 me conté a mí misma cuando quedé sola" (Carpentier, 2004 [1978]: 663). 
diferentes, pues Stendhal no logra equilibrar las múltiples situaciones y personajes que producen el conflicto, en tanto que el problema de Carpentier subyace en la relación desproporcionada entre los eventos vinculados por relaciones de causalidad y temporalidad (de 38 hechos narrados apenas 5 son asociaciones de tipo causal), situación que origina que su lectura sea excesivamente intelectual, mientras que con Stendhal se tiene la sensación de leer un texto que ha sido escrito apresuradamente. En relación con sus pensamientos filosóficos y la forma de introducción en el texto, la filosofía de Stendhal se percibe a través de la configuración del personaje de Fabrice, en tanto que en Carpentier se evidencia mediante la manera de enunciar el relato, es decir, en la parte formal del texto.

\section{ACCIÓN NARRATIVA}

La acción en el texto de Stendhal se configura mediante la mirada psicológica de sus personajes. Mirar no es simplemente ver $^{29}$, es más bien un proceso donde lo que se observa se reflexiona. Los personajes de Stendhal piensan constantemente acerca de lo observado. Por ejemplo, Fabrice se interroga en Waterloo si lo que está contemplando es o no una batalla:

[...] et Fabrice devint comme un autre homme, tant il fit de réflexions profondes sur les choses qui venaient de lui arriver. Il n'était resté enfant que sur un point: ce qu'il avait vu, était-ce une bataille, et en second lieu, cette bataille était-elle Waterloo? (Stendhal, 2000 [1839]: 117).

También durante sus aventuras amorosas no deja de cuestionarse si tal experiencia es el amor real:"Mais n'est-ce pas une chose bien plaisante, se disait-il quelquefois, que je ne sois pas susceptible de cette préoccupation exclusive et passionnée qu'ils appellent de l'amour?" (Stendhal, 2000 [1939]: 295). Y es que la causa que moviliza el texto no son las situaciones que les suceden a los personajes. Si así fuera, la novela sería un relato de aventuras más ${ }^{30}$. Evidentemente, en un primer nivel lo que impulsa a la narración son los

29 En el idioma francés mirar (regarder) no es simplemente ver (voir). Equivale más a la palabra observar, entendida ésta como examinar o escrutar un objeto más allá del dato sensorial:"Regarder [...] s'appliquer à voir (qqn, qqch.) examiner, observer" (Le Robert Micro, 2006: 1130).

30 Michel Crouzet, apoyándose en Paul Ricœur, es de la opinión que La Chartreuse de Parme, además de ser una novela de aventuras, es también un relato filosófico: "Bourré d'actions, le roman se sépare de l'évolution moderne du genre, où le roman d'action laisse la place au roman de caractère et celui-ci au roman de pensé, selon l'analyse de Paul Ricœur qui discerne une défaite progressive de l'intrigue, ou du principe de configuration formelle par la expansion du caractère aux dépens de l'intrigue" (Crouzet, 2000: $X V)$. 


\section{DE LA PRIMAVERA)}

giros de situaciones y los desplazamientos de los personajes, pero la auténtica fuerza que dinamiza el texto es lo que los personajes observan, entendiendo lo observado como un proceso reflexivo acerca de lo vivido ${ }^{31}$. Por ello, el lector únicamente puede acceder -y avanzar en la lectura- a través de las particulares miradas reflexivas de los protagonistas.

Ahora bien, no se trata de que la instancia narrativa reproduzca simplemente lo que cada personaje percibe, sino que la visión de mundo se constata mediante la interrelación de las distintas formas de percibir el mundo. Empleando los conceptos de Bajtín, lo que específicamente mueve el texto es la polifonía o el dialogo de consciencias ${ }^{32}$. La polifonía no consiste en cambios de registros a nivel de instancias narrativas, esto contribuye a la verosimilitud del relato pero no a un diálogo de consciencias. El dialogismo de Bajtín radica en la confrontación de dos o más puntos de vista que no necesariamente van acompañados de vistosos artificios literarios.

Identificamos tres puntos de vista en La Chartreuse de Parme acerca de la vida, perspectivas que se encarnan en lo que cada personaje representa en el relato. Fabrice es idealista y busca vivir su vida en correspondencia a sus ideales: "Je me compare toujours à un modèle parfait, et qui ne peut exister" (Stendhal, 2000 [1839]: 234). Gina, a pesar de comprender la naturaleza soñadora de su sobrino, sabe que su forma de vida es imposible de realizar, y por eso propone un equilibrio entre los ideales y las posibilidades reales de cumplirlos. Para llevar a cabo esta forma de existencia vive el presente aceptando lo que la vida le ofrece: "La vie s'enfuit, ne te montre donc point si difficile envers le bonheur qui se présente, hâte-toi de jouir" (Stendhal, 2000 [1839]: 53); en tanto Fabrice, en conflicto con el presente, busca cosas (como la gloria) que solo el futuro le puede proporcionar. Mientras Gina es capaz de vivir y ser feliz con lo mundano, lo terrenal, Fabrice necesita de las ideas para encontrar placer. Finalmente se encuentra Mosca (el terzo incomodo), que simboliza la actitud pragmática y oportunista que algunos hombres adoptan para afrontar la existencia: "De tous temps les vils Sancho Pança l'emporteront à la longue sur les sublimes don Quichotte" (Stendhal, 2000 [1839]: 244). No tiene las ilusiones de Fabrice ni la pasión meridional de Gina, sin embargo, encarna a la perfección el arte de sobrevivir. Pero el motor del drama no es la caracterización de los personajes, sino, como

31 Es la lucha entre percepción y sensación que Jean Starobinski plantea: “¿Qué significa en el pasaje que acabamos de citar, la distinción entre sensación y percepción? [...] la percepción le roba la sensación, se interpone entre el mundo y él, le impide estar presente. Conocer lo que se experimenta, es no estar ya del todo en ello, es arrancarse a ello. Al contrario que la sensación que es pura participación, pura adhesión al mundo, la percepción es una ruptura; más aún, llega a petrificar la sensación, que muere antes incluso de abrirse" (Starobinski, 2002 [1961]: 184).

32 Bajtín define la polifonía de la siguiente manera: “Empleando la paradoja, se podría decir que Dostoievski no pensaba mediante ideas, sino mediante puntos de vista, conciencias, voces. Trataba de percibir y formular todo pensamiento, de tal manera que en él se expresara y se revelara el hombre total y, por lo mismo, toda su visión de mundo, de alfa a omega, en forma resumida" (Bajtín, 2012 [1979]: 196-197). 
ya se ha dicho, la confrontación de los puntos de vista que ellos representan. Tal disputa nace a partir de un incidente, el asesinato cometido por Fabrice. La novela es la narración de dicha situación, mas este hecho solo es un pretexto para un problema filosófico que plantea Stendhal: el combate a la modernidad. De modo que Fabrice, Gina y Mosca simbolizan tres respuestas del ser frente a la vida moderna: el idealismo, el equilibrio o la pasión meridional, y el oportunismo o pragmatismo. En consecuencia, el principio que dinamiza la acción en La Chartreuse de Parme es el diálogo entre consciencias.

Pero la polifonía no consiste únicamente en mostrar las distintas perspectivas acerca del objeto, antes de ello es necesario un sujeto que reflexione sobre sí mismo, es decir, que sea consciente. La manera de representar narrativamente a un personaje consciente es mostrando al lector su evolución a lo largo del relato. No debe entenderse evolución como crecimiento en sentido positivo, sino simplemente como sinónimo de cambio o de mutación. Por ejemplo, Stendhal necesita mostrar a Fabrice desde que es un adolescente ingenuo hasta que se convierte en un hombre consumido que va morir a una cartuja en absoluta soledad. Lo mismo ocurre con Gina, de ser una chica jovial y alegre se transforma en una mujer fría capaz de actos blâmables. Y qué decir del conde Mosca, que pasa de ser un estratega frío, calculador, a convertirse en un devoto manipulable y leal a la duquesa Sanseverina. Por ello, puede afirmarse que la representación del tiempo en la novela es lineal y progresivo, ya que es necesario que el lector observe el porqué de los cambios en los protagonistas, y su transformación tiene que ser claramente perceptible. De ahí que Stendhal (2000 [1840]: 731) no admitiera el consejo -dado por Balzac- de suprimir por completo los episodios concernientes a la adolescencia de Fabrice, y tampoco aceptara el empleo de artificios literarios para la recreación del tiempo, pues los cambios solo son constatables cuando el lector tiene la impresión de que está leyendo la vida entera de los personajes, y no un evento o una fábula, mucho menos un artificio literario.

A diferencia de Stendhal, en la escritura de Carpentier no hay polifonía, por tanto no existen personajes y apenas hay conflicto, de ahí la inquietud sobre el elemento qué dinamiza el texto, pues al no existir situaciones -conflictos- no hay nada que subordine el tiempo al relato. Al igual que ocurre con Stendhal, lo que moviliza en un primer nivel la narración en Carpentier son los cambios de situaciones, que en este caso no son demasiados. Al ser la historia de amor entre Vera y Enrique lo que se cuenta, son tres los momentos que constituyen la bisagra que hacen avanzar la lectura: la aventura entre Enrique y Teresa, la revelación de tal amorío a Vera y el regreso de ésta con Enrique. Pero, como ya se ha mencionado, desde este punto de vista el drama es imperfecto, pues carece de un auténtico desenlace (una catástrofe). De esto se infiere que el escritor quiere que su relato se lea de otra manera, es decir, la lectura no debe ceñirse al orden causal de los hechos, sino al principio temporal-ideológico. 


\section{DE LA PRIMAVERA)}

Dentro de esta perspectiva, la historia narrada es la relación de los protagonistas con las revoluciones, siendo la voz del narrador la que controla de forma absoluta el tiempo representado en la narración. No se puede decir que esta voz narrativa sea una intromisión, puesto que es omnipresente (la novela es narrada por ella). A pesar de que tal instancia narrativa se disfraza de la participación de Vera alternada con la intervención de Enrique, en realidad es una única voz (recuérdese que no hay personajes ya que no existen diferentes puntos de vista). De manera que el tiempo del narrador controla arbitrariamente al tiempo representado por la fábula. Ello significa que la acción narrativa no se encuentra en lo que el relato cuenta, sino en la manera en que el escritor narra la historia. La acción no reside en el interior del texto, habita fuera de él, en la forma de enunciar los eventos. Así pues, el artificio literario por medio del cual algunos capítulos son presentados por Vera y otros por Enrique es lo que marca el ritmo de la narración. Tal situación es posible por el empleo del soliloquio y la analepsis. Al ser el soliloquio un monólogo que no espera respuesta directa de un interlocutor, le permite al escritor controlar el tiempo a su voluntad. El narrador no debe ceñirse al orden del tiempo de lo que se está contando, puede contar un asunto presente, pasado o futuro sin respetar el tiempo del evento principal narrado, e introducir tales episodios cuando mejor le plazca. En La consagración de la primavera las retrospecciones se encuentran situadas al principio y al final del relato (véase esquema 4), lo que causa la sensación de que el tiempo se dilata. Por otro lado, esto indica además que la estructura del texto se presta mejor a un relato corto que a una narración de grandes proporciones teniendo la analepsis la función de convertir una nouvelle en una novela.

En definitiva, la acción narrativa se desarrolla en Stendhal mediante la pluralidad de voces - La Chartreuse de Parme es la descripción de tal diálogo- a través de un tiempo lineal y progresivo, mientras que en Carpentier sucede lo contrario, la acción narrativa se configura por medio de una única voz, y la lectura avanza gracias a una única conciencia, es decir, el tiempo del narrador.

\section{CONCLUSIONES}

La realidad se representa en Stendhal mediante la creación de infinidad de situaciones. Estas situaciones son espacios donde se producen interacciones, relaciones y, por ende, conflictos entre los distintos personajes. El vínculo entre situaciones y personajes es de tipo simbiótico, es decir, las situaciones no crean a los personajes ni a la inversa, son los intercambios de un mínimo de caracteres los que dan nacimiento a ambos y, a su vez, esta combinación engendra el espacio que recrea lo real. En la narrativa de Stendhal el espacio no existe independiente de la actividad que lo constituye, no se encuentra 
sustantivado, es más bien una abstracción de las relaciones entre los actantes del relato. Podría afirmarse que la realidad evocada por el escritor francés es dinámica.

El principio rector que orienta la manera en que se encadenan los eventos narrados en La Chartreuse de Parme es ideológico, lo cual quiere decir que la norma que debe emplearse para valorar la novela debe ser la filosofía del autor, por lo que los errores estructurales achacados a su poética no deben tomarse como tales, pues sin esas supuestas faltas el relato no tendría razón de ser, y Stendhal dejaría de ser Stendhal.

El narrador incorpora la filosofía en el texto a través del retrato psicológico de sus personajes, que no es un inventario de sus características, es la mirada reflexiva (le regard) con que ellos observan los hechos. El lector ve lo que el personaje contempla como si el héroe stendhaliano llevara consigo una cámara cinematográfica al hombro. Así pues, el paisaje en Stendhal no consiste en la descripción de los objetos, es la narración de un objeto a partir de un sujeto que observa, de forma que objeto y sujeto se convierten en una misma cosa, o también podría decirse que es la apropiación del objeto por parte del sujeto.

El principio motor de la narración es la polifonía, pero para que suceda es imprescindible desarrollar personajes reflexivos. Representar narrativamente el diálogo de consciencias y protagonistas conscientes de sí mismos implica narrar la totalidad de sus vidas y no únicamente fragmentos, episodios o anécdotas de sus existencias, pues se tiene que consignar su metamorfosis. Esto es así porque reflexión y polifonía no son algo estático, son desplazamiento, flujo, movimiento. En consecuencia, el tiempo simbolizado en La Chartreuse de Parme es lineal y progresivo. La sensación comprimida que se tiene al leer la novela es producto de la angustia de un escritor romántico que aspira a fijar algo imposible de sujetar: el dinamismo de lo real. Y es que todo romántico sabe que ante tal reto lo único que puede hacer es señalar el ritmo hacia donde marcha la realidad, puesto que entre escritura y realidad existe una tensión insuperable, debido a que la naturaleza de la primera es permanencia y pasividad, en tanto que la segunda es actividad y mutación.

Si el tiempo en Stendhal es oscilación, en Carpentier es estático, nada fluye en sus novelas, pues la realidad evocada en su narrativa se encuentra cosificada. Sus relatos serían la explicación de una serie de objetos que, a diferencia de Stendhal, el sujeto nunca se apropia de ellos, permanece siempre a distancia, haciendo circunvalaciones, buscando las palabras que mejor los definan. Esta diferencia entre ambos escritores es importante, ya que mientras el narrador francés busca la relación de objetos, el cubano pretende conceptualizarlos, para lo cual necesita inmovilizar lo real, siendo su estética la descripción de una realidad anquilosada.

Pero narrar una realidad inmóvil plantea un problema para el escritor, sobre todo si se entiende la novela como la narración de un conflicto pues, a partir de esta premisa, 


\section{DE LA PRIMAVERA)}

la representación de lo real no puede ser algo estático. De ahí surge la duda de cómo Carpentier estructura el conflicto narrativo cuando no comparte el principio básico de la novela, que es el movimiento.

La solución encontrada por el cubano es enfatizar en la enunciación del relato, y no en los hechos sobre los que se basa la fábula. Lo más importante en La consagración de la primavera es la forma en que el escritor se expresa, y no los eventos narrados en sí mismos. Para llevar a cabo esta operación, Carpentier otorga al narrador poderes omnímodos, de tal modo que es el narrador quien determina con absoluta arbitrariedad el conflicto de la novela. Es decir, la configuración del conflicto en el texto no surge a partir de la causalidad de los eventos narrados, mucho menos de las relaciones de los personajes, se origina en función de la explicación de un objeto - un tema- por parte del narrador. Por ello, a pesar de que en La consagración de la primavera los hechos vinculados por relaciones de tipo causal orientan la historia a un relato amoroso, el narrador encauza el conflicto al tema que a él le interesa exponer: las relaciones entre el intelectual y la revolución. Así consigue que el conflicto no se encarne en la acción narrativa, sino que se intelectualice a través de un tema. En consecuencia, el espacio no se origina a partir de los eventos narrados, se circunscribe al objeto que el narrador incorpora caprichosamente en el relato.

Lo mismo ocurre con el tiempo. Este no es producto de la causalidad de la ficción, está condicionado por el discurso del narrador o el tiempo de la escritura. Mientras que en el relato clásico europeo el tiempo se subordina a la cronología de los sucesos relatados, en la novela de Carpentier el tiempo deviene del narrador, que se esconde en las falsas voces narrativas de Vera y de Enrique. Cada capítulo está contado por uno de los protagonistas, pero al no existir un drama no puede decirse que estas voces los representen, en realidad es una única voz narrativa la que relata la historia. La alternancia solamente tiene la función de marcar el ritmo, el tiempo de la narración, haciendo posible la analepsis o incluso dando por finalizado el relato. En otras palabras, La consagración de la primavera es un monólogo. Mientras que en Stendhal el texto lo mueve la polifonía, el principio motor de la acción narrativa en Carpentier es el soliloquio.

En el único elemento que coinciden ambos escritores es que tanto La Chartreuse de Parme como La consagración de la primavera son novelas ideológicas. Al igual que a Stendhal, a Carpentier no le interesa contar un relato amoroso, este solo es un pretexto para introducir su visión de mundo, que consiste en entender la existencia como repetición, destino y fatalidad. Ahora bien, la forma en que la ideología penetra en el texto es diferente en cada caso. Mientras Stendhal lo hace a través de la configuración de personajes, Carpentier lo realiza mediante la enunciación del relato (la trama). Es decir, para percibir la filosofía del autor es necesario fijarse en la estructura circular de la novela. Los hechos que componen las existencias de los protagonistas se repiten una y otra vez. La vida amorosa de Enrique y Vera es una repetición de sus experiencias con 
sus antiguos amores. Por otra parte, como ya hemos mencionado, el conflicto narrativo no sucede entre ellos, sino entre cada uno de los héroes con una serie de eventos históricos que simbolizan a las revoluciones, convirtiendo sus vidas en un eterno huir de las revoluciones. De este modo, la inestabilidad política se vuelve una constante en sus existencias, a tal grado que podemos hablar de fatalidad.

Por su grado de experimentación, La consagración de la primavera resulta muy interesante para los estudiosos de la literatura. Es muy probable que Carpentier estuviera familiarizado con las ideas estéticas de Lukács, y que con esta novela pretendiera llevar a la práctica algunos de sus postulados. A pesar de que el pensador húngaro era un admirador de la novela europea del sigloXIX, consideraba (Lukács, 2011 [1935]:43) que sus técnicas (el drama y el héroe problemático) ya no podían representar adecuadamente la realidad moderna. En su afán de desarrollar una estética acorde al pensamiento marxista, planteó que la novela futura debía ser un epos sin drama ${ }^{33}$, tal y como era en el mundo griego. Nuestro análisis confirma que Carpentier quería crear un gran relato épico, no obstante, cometió un error: intelectualizó demasiado el conflicto. El mismo Lukács (2011 [1935]: 47) criticó a los escritores modernos por considerar que configuraban la acción narrativa de forma excesivamente abstracta, haciendo que la novela pareciera muy artificial, forzada, tal y como resulto ser La consagración de la primavera. Sin embargo, de la misma manera que no se le puede exigir a Stendhal que equilibre mejor sus acciones dramáticas, tampoco se le puede pedir a Carpentier que desarrolle un auténtico drama y que confeccione mejor sus personajes. Hacerlo equivaldría a privarles de sus genios artísticos. Lo que evidencia estos desaciertos no son defectos en sus escrituras, se trata más bien de la relación problemática entre ideología y escritura, entre lo que el escritor quiere escribir y aquello que se puede narrar; aunque, por otra parte, este problema es natural cuando se utiliza la literatura como medio para reflejar la realidad.

En conclusión, la forma que tienen Stendhal y Carpentier de representar lo real es antagónica. La realidad en Stendhal es energía, movimiento y velocidad. Para recrearla profundizó en la construcción del personaje, y como muchos escritores de su época incorporó el drama en sus relatos, lo que dio como resultado un tipo específico de narración, que hasta el día de hoy, en el mundo occidental, continua siendo el canon de la novela. Por el contrario, la realidad en Carpentier es quietud, inercia e inmovilidad, y se representa

33 Lukács creía que el drama era consecuencia de las contradicciones de la sociedad capitalista. En el comunismo estas contradicciones ya estarían superadas, por eso la épica sería un género narrativo más apropiado: "En la medida en que el epos trabaja con un héroe que se ha formado en toda su psicología sin entrar en una relación problemática con la sociedad en la que vive, la configuración épica no requiere ningún tipo de explicaciones genéticas; es decir que puede comenzar en el punto que resulte más propicio para el desenvolvimiento de los sucesos épicos. La narración del pasado solo sirve a los intereses de la narración, al desenvolvimiento de la imagen del mundo, a la tensión épica, etcétera, y no a una explicación del carácter del héroe y de su relación con la sociedad" (Lukács, 2011 [1935]: 69) 
mediante la descripción poética de objetos o temas. Además, el rechazó de Carpentier al empleó del drama y la falta de configuración de personajes, dio como resultado un tipo de relato en el que la forma de enunciación es más importante que lo que se cuenta. Pese a estas diferencias algo mantienen en común, tanto Stendhal como Carpentier estaban convencidos del poder de la literatura para expresar fielmente la realidad.

\section{REFERENCIAS BIBLIOGRÁFICAS}

AUERBACH, E. (2011 [1942]. Mimesis. La representación de la realidad en la literatura occidental. México D.F.: Fondo de Cultura Económica.

BAJTíN, M. (2012 [1979]). Problemas de la poética de Dostoievski. México D.F.: Fondo de Cultura Económica.

BALZAC, H. (1972 [1840]). "Études sur M. Beyle (Frédéric Stendhal)". En La Chartreuse de Parme, Stendhal, 626-634. Saint-Amand: Gallimard.

BLIN, G. (1973 [1954]). Stendhal et les problèmes du roman. París: Libraire José Corti.

CARPENTIER, A. (1981). La novela latinoamericana en vísperas de un nuevo siglo y otros ensayos.

Madrid: Siglo Veintiuno de España Editores.

(2004 [1978]): La consagración de la primavera. Madrid: Alianza Editorial.

CROUZET, M. (2000). "Préface". En La Chartreuse de Parme, Stendhal, VII-LI. París : Libraire Générale Française.

(2010). Regards de Stendhal sur le monde moderne. París : Editorial Kimé.

DEL PRADO, J. (2009). “La narración”. En Historia de la literatura francesa, J. Del Prado (ed.), 791 923. Madrid: Cátedra.

ESTÉBANEZ, D. (2008 [1996]). Diccionario de términos literarios. Madrid : Alianza Editorial.

FRANCO, J. (2009 [1973]. Historia de la literatura hispanoamericana. A partir de la independencia.

Barcelona: Ariel.

GENETTE, G. (1989 [1972]. Figuras III. Barcelona : Editorial Lumen.

(2002 [1987]). Seuils. París : Éditions du Seuil.

GONZÁLEZ, R. (2004 [1993]). Alejo Carpentier: El peregrino en su patria. Madrid: Editorial Gredos. KAYSER, W. (1992 [1954]). Interpretación y análisis de la obra literaria. Madrid: Editorial Gredos.

LE ROBERT MICRO. (2006). Dictionnaire de la langue française. París: Edición Dictionnaire Le Robert.

LUKÁCS, G. (2010 [1920]). Teoría de la novela. Un ensayo histórico filosófico sobre las formas de la gran literatura épica. Buenos Aires: Ediciones Gogol.

(2011 [1935]. Escritos de Moscú. Estudios sobre política y literatura. Buenos Aires: Editorial Gorla.

STAROBINSKI, J. (2002 [1961]). El ojo vivo. Madrid: Cuatro Ediciones.

STENDHAL (1958 [1830]). Le Rouge et le Noir. París: Libraire Générale Française. 
(1972 [1839]). La Chartreuse de Parme. Saint-Amand: Gallimard.

(2000 [1839]). La Chartreuse de Parme. París: Libraire Générale Française.

(2000 [1840]). "Projets de réponse de Stendhal au grand article de Balzac". En La

Chartreuse de Parme, Stendhal, 723-735. París: Libraire Générale Française.

TODOROV, Tz. (2004 [1968]). Poética estructuralista. Buenos Aires: Editorial Losada.

TOMACHEVSKI, B. (1982 [1928]). Teoría de la literatura. Madrid: Akal.

Recibido el 3 de enero de 2016.

Aceptado el 14 de noviembre de 2016. 